\title{
Lack of Efficacy
}

National Cancer Institute

\section{Source}

National Cancer Institute. Lack of Efficacy. NCI Thesaurus. Code C48226.

The lack of expected or desired effect related to a therapy. 